\title{
Synthesis and Structural Properties of Nanocomposites Based on Synthetic Opals and Active Dielectrics
}

\author{
Bilal Abu Sal ${ }^{1}$ \\ ${ }^{1}$ Tafila Technical University, Applied Physics Department, Tafila 66110, P.O. Box 179, Jordan \\ Correspondence: Bilal Abu Sal, Tafila Technical University, Applied Physics Department, Tafila 66110, P.O. Box \\ 179, Jordan.E-mail: abusal@ttu.edu.jo,bilal_abu@hotmail.com
}

Received: November 18, 2019

Accepted: December 1, 2019

Online Published: December 2, 2019

doi:10.5539/apr.v12n1p19

URL: http://dx.doi.org/10.5539/apr.v12n1p19

\begin{abstract}
This work is devoted to generalize and analyze the previous results of new photonic-crystalline nanomaterials based on synthetic opals and active dielectrics. Data were characterized by X-ray diffraction and Raman spectroscopy. Active dielectrics infiltrated into the pores of the opal from the melt. The phase structure composition of the infiltrated materials into the pores of the opal matrix were analyzed. The results of $\mathrm{x}$-ray diffraction and Raman spectra allowed to establish the crystal state of active dielectrics in the pores of the opal. The Raman spectra of some opal-active dielectric nanocomposites revealed new bands and changes in band intensities compared to the spectra of single crystals of active dielectrics. Further more, differences in band intensities in the spectra were measured at different spots of the sample's surface were observed. The revealed changes were attributed to the formation of new crystalline phases due to the injected dielectrics in opal pores.
\end{abstract}

Keywords: Raman scattering, synthetic opals, Active dielectrics, Nanocomposites, Nanocrystals

\section{Introduction and Background}

Optical properties of new materials based on synthetic opals and matrix nanocomposites with active dielectrics attract researches in the field of low-dimensional physical systems. Special interest from a practical point of view are 3D-periodic structures of nanocrystals of active dielectrics, which have both nonlinear optical and photonic crystal properties, and hence new possibilities for controlling light beams. A problem of formation of bulk properties of solids with an increase in the number of structural elements was discussed earlier (Gubin \& Moiseev, 1987; Gusev \& Rempel', 2004; Petrov, 1986). The method of dispersion of inorganic substances in the system of cavities and channels of regular porous dielectric matrices (zeolites and opals) proposed by V. N. Bogomolov has great possibilities (Astratov et al., 1995; Bogomolov, 1978). This method makes it possible to obtain ensembles of identical, ordered nanoclusters with a high concentration. On the other hand, opal-based nanocomposites can be considered as model for a wide class of materials with nano-sized pores of different morphologies. At the same time, it is necessary to note the paucity of available data on nanostructures in terms of substances chosen as objects of research. This is due to the limited capabilities of the technology for their production and experimental methods for studying the physical properties of matrix nanocomposites. Additional difficulties in the study of matrix nanocomposites based on synthetic opals are associated with the presence of structural defects in the initial matrix (Moiseyenko et al., 2015). Insufficient experimental material makes it difficult to develop the physics of composites with nanostructured inorganic and organic substances. This work is aimed to analyze previous obtained results of new matrix nanocomposites based on synthetic opals and active dielectrics (Abu et al., 2013; Derhachov et al., 2018; Derhachov et al., 2019; Moiseienko et al., 2016; Moiseienko et al., 2016; Moiseyenko et al., 2018) in order to identify the most common structure patterns formed due to various infiltrated materials.

\section{Experimental Details}

Bulk synthetic opals were grown using synthesized the modified Stöber method by slow crystallization monodisperse colloidal suspension of globules $\alpha-\mathrm{SiO}_{2}$ (Stöber, Fink, \& Bohn, 1968). The hydrolysis of tetraethoxysilane was carried out in an aqueous-alcoholic medium in the presence of ammonia as a catalyst. The molar ratio of the components in the reaction mixturewas: $\mathrm{NH}_{4} \mathrm{OH}: \mathrm{H}_{2} \mathrm{O}: \mathrm{C}_{2} \mathrm{H}_{5} \mathrm{OH}: \mathrm{Si}\left(\mathrm{OC}_{2} \mathrm{H}_{5}\right)_{4}=1-3: 19-21$ : $11: 0.14$. 
Synthetic opals were obtained by natural sedimentation in isothermal conditions at $T=20^{\circ} \mathrm{C}$. Diameter $D$ of globules and distance $d$ between (111) planes were determined from the position of the maximum $\lambda_{m}$ in the Bragg reflection spectra of the initial opals using the Bragg law $\lambda_{m}(\theta)=2 d \sqrt{\varepsilon_{e f f}-\sin ^{2} \theta}$, where $\theta$ angle of incidence of light on a system of (111) planes, $D=d \sqrt{3 / 2}, \varepsilon_{e f f}-$ effective dielectric constant. The latter value is determined by the sum of the contributions of the dielectric permittivity $\varepsilon_{i}$ of substances in the pores of opal, depending on their volume part $f i\left(\varepsilon_{e f f}=0.74 \cdot \varepsilon_{S i O_{2}}+\sum_{i} f_{i} \cdot \varepsilon_{i}, \sum_{i} f_{i}=0.26\right)$.

In the case of the original opal (in the pores - air filled) value $\varepsilon_{\text {eff }}$ was 1.6. For different samples, the values of the diameter $D$ of the globules and the interplanar distance $d$ were found to vary within $D=295-306 \mathrm{~nm}, d=241-$ $250 \mathrm{~nm}$. The spectral position of the photon stop zone band for samples of initial opals corresponded to the interval $593-614 \mathrm{~nm}$ in (111) direction. The filling of the pores of opal samples was carried out by their impregnation with a melt of a single crystal under the influence of capillary forces (Kurdyukov et al., 2011; Moiseyenko et al, 2018). The fact of the melt entering the opal pores was recorded by the shift of the maximum of the Bragg reflection band in the long - wave region. Based on a comparison of the position of the maxima for the measured reflection spectra of nanocomposite samples and calculated $\lambda_{m}$, values provided $100 \%$ filling the pores within the substance, the grade of filling the pores, which composed to $\sim 50 \%$ vol. was defined.

Images of the initial globules were obtained using scanning electron microscope SEM, characterisation the surface of the initial opal and infiltrated samples with active dielectrics, carried out by microanalyzer JEOL-JXA-8200.

X-ray Diffraction Pattern was measured using the $\left(\mathrm{Cu} \mathrm{K}_{\alpha}\right)$ radiation. Raman spectra was carried out in geometry "on reflection" using confocal Raman microscope LabRamHR800 (HORIBA Scientific, Jobin Yvon). The Raman spectra were measured at various spots of the (111) surface of the samples at room temperature after removing of melt residues from the surface by grinding.

\section{Results and Discussion}

A typical view for the surface of samples of synthetic opal after high-temperature treatment at $T=850^{\circ} \mathrm{C}$, are shown in Figure 1.

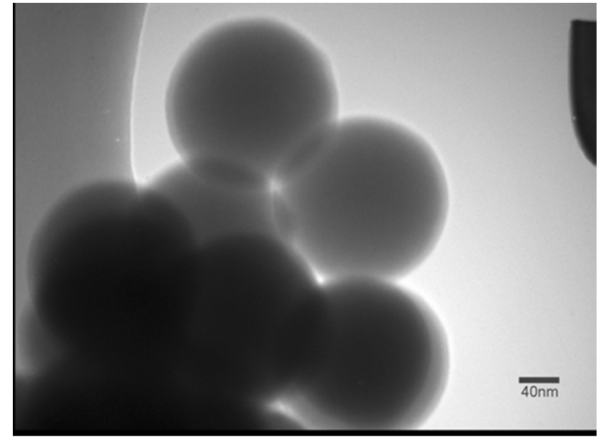

a

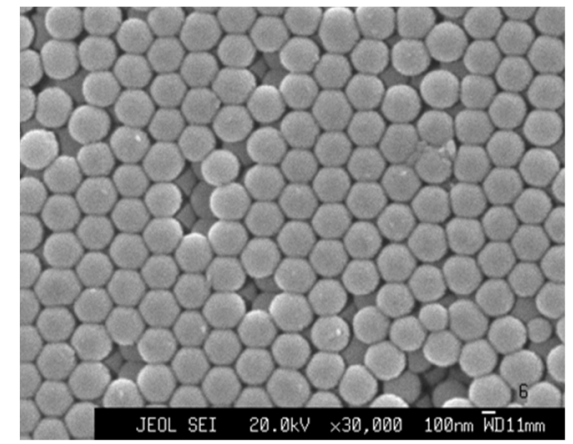

$\mathrm{b}$

Figure 1. SEM Image of the shape of the initial globules (a) and the surface of the initial opal after high-temperature annealing at $\mathrm{T}=850^{\circ} \mathrm{C}(\mathrm{b})$

Figure $1 \mathrm{~b}$ shows the surface of opal sample after high-temperature annealing, the globules are sintered and acquire a hexagonal shape, and the pore size is reduced. Surface's Images of the opal - active dielectricsamples after melting and crystallization of the melt at different magnifications were obtained in Figure 2a-e.

Raman spectra of initial crystals of active dielectrics were studied in detail by different research groups $\left(\mathrm{Bi}_{12} \mathrm{SiO}_{20}\right.$ (Venugopalan \& Ramdas, 1972), $\mathrm{Bi}_{2} \mathrm{TeO}_{5}$ (Domoratskii et al., 2000), $\mathrm{TeO}_{2}$ (Champarnaud-Mesjard et al., 2000), $\mathrm{NaBi}\left(\mathrm{MoO}_{4}\right)_{2}$ (Moiseenko, Bogatirjov, Jeryemenko, \& Akimov, 2000), $\mathrm{Pb}_{3}\left(\mathrm{P}_{0.5} \mathrm{~V}_{0.5} \mathrm{O}_{4}\right)_{2}$ (Salje \& Iishi, 1977)).

$\mathrm{X}$-ray diffraction pattern and Raman spectrum of the nanocomposite opal $-\mathrm{Bi}_{12} \mathrm{SiO}_{20}$ shown in Figure 3. 
A comparative analysis of the measured diffraction pattern of the nanocomposite with X-ray diffraction for $\mathrm{Bi}_{4} \mathrm{Si}_{3} \mathrm{O}_{12}$ crystals (Derhachov et al., 2019; Liu \& Kuo, 1997), as well as Raman spectra of nanocomposite with spectra of single crystals $\mathrm{Bi}_{12} \mathrm{SiO}_{20}$ (Venugopalan \& Ramdas, 1972) and $\mathrm{Bi}_{4} \mathrm{Si}_{3} \mathrm{O}_{12}$ (Beneventi, Bersani, Lottici, \& Kovacs, 1995), allowed to establish a dominant presence in the pores of opals, the nanocrystals of bismuth orthosilicate $\mathrm{Bi}_{4} \mathrm{Si}_{3} \mathrm{O}_{12}$, which is formed in the pores of the opal due to the interaction of the melt $\mathrm{Bi}_{12} \mathrm{SiO}_{20}$ with the $\mathrm{SiO}_{2}$ surface global.

The most intense peaks on the X-ray diffraction correspond to the crystal phase $\mathrm{Bi}_{4} \mathrm{Si}_{3} \mathrm{O}_{12}$ (Liu \& Kuo, 1997). In the Raman spectrum of opal sample $-\mathrm{Bi}_{12} \mathrm{SiO}_{20}$ the frequencies of the bands characteristic of crystals are indicated to $\mathrm{Bi}_{4} \mathrm{Si}_{3} \mathrm{O}_{12}$ (Beneventi, Bersani, Lottici, \& Kovacs, 1995).

$\mathrm{X}$-ray diffraction pattern and Raman spectrum of the nanocomposite opal $-\mathrm{Bi}_{2} \mathrm{TeO}_{5}$ shown in Figure 4 . The positions of the peaks on the X-ray diffraction pattern correspond to the $\mathrm{Bi}_{2} \mathrm{TeO}_{5}$ crystal phase (Mercurio, $\mathrm{El}$ Farissi, Frit, \& Goursat, 1983). Comparison the measured spectra of opal nanocomposite $-\mathrm{Bi}_{2} \mathrm{TeO}_{5}$ with spectra of single crystals $\mathrm{Bi}_{2} \mathrm{TeO}_{5}$ (Domoratskii et al., 2000) it revealed a number of new weak bands as shown in (Figure 4, b). In addition, the spectral intensity distribution in the frequency range $100-550 \mathrm{~cm}^{-1}$ was markedly different at different points on the surface of the opal- $\mathrm{Bi}_{2} \mathrm{TeO}_{5}$ sample while in the region $600-950 \mathrm{~cm}^{-1}$ the nature of the spectral distribution persisted.

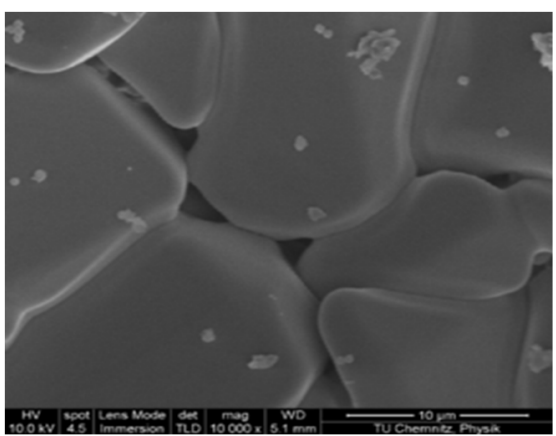

a

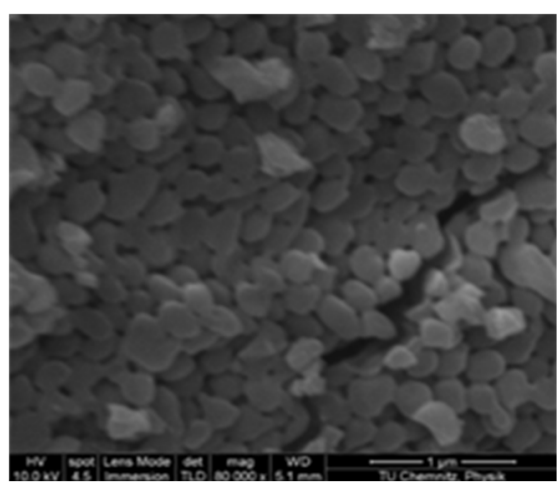

c

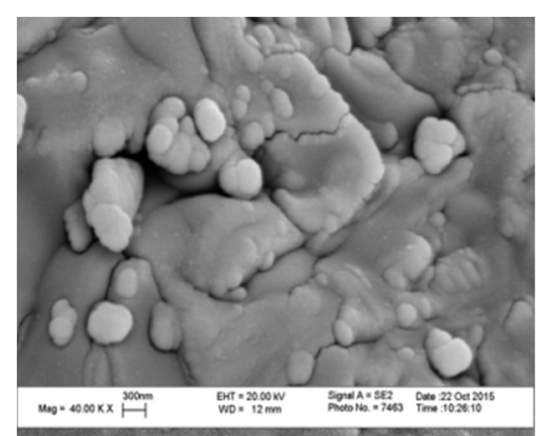

b

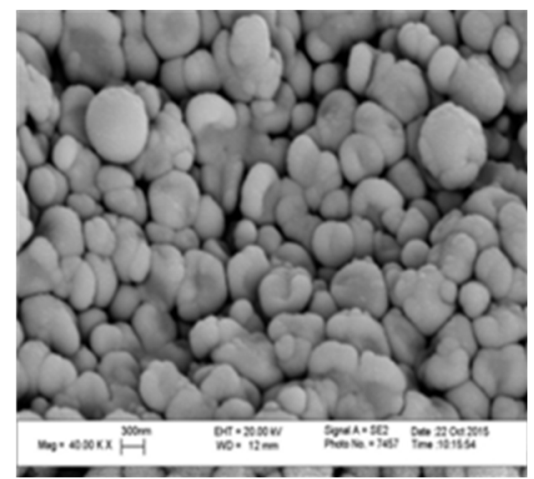

d

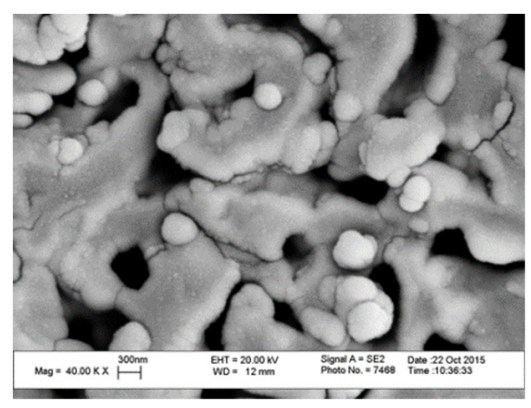

e

Figure 2. SEM Images of opal sample surface $-\mathrm{Bi}_{12} \mathrm{SiO}_{20}(\mathrm{a})$, opal $-\mathrm{Bi}_{2} \mathrm{TeO}_{5}(\mathrm{~b})$, opal - $\mathrm{TeO}_{2}(\mathrm{c})$, opal $\mathrm{NaBi}\left(\mathrm{MoO}_{4}\right)_{2}(\mathrm{~d})$ and opal - $\mathrm{Pb}_{3}\left(\mathrm{P}_{0.5} \mathrm{~V}_{0.5} \mathrm{O}_{4}\right)_{2}$ (e) after melting and crystallization of the melt. 


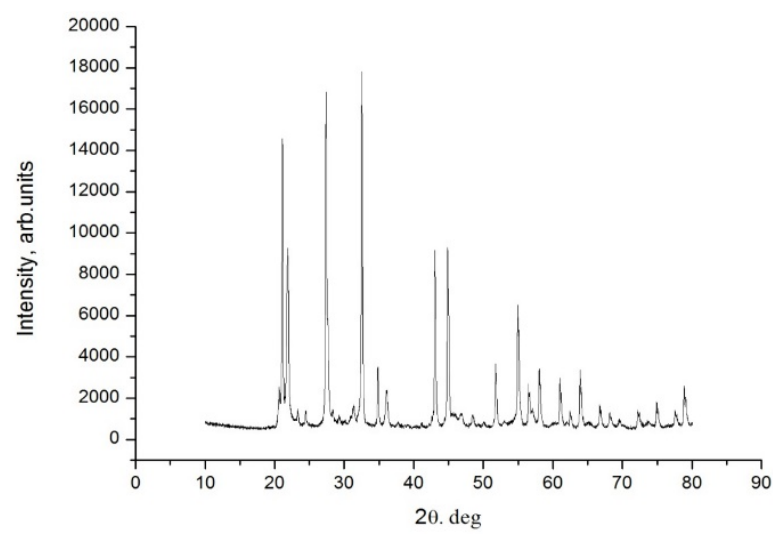

a

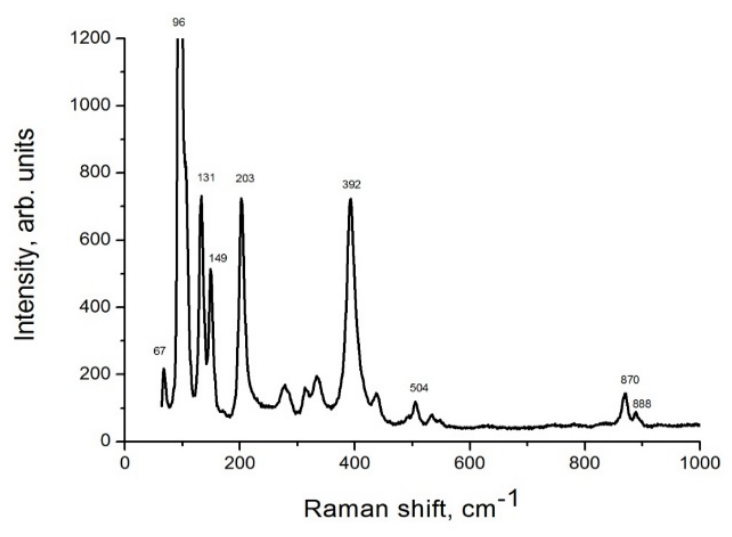

b

Fig 3. X-ray diffraction pattern (a) and Raman spectrum of the nanocomposite opal - $\mathrm{Bi}_{12} \mathrm{SiO}_{20}$ (b), measured from the (111) surface of the sample

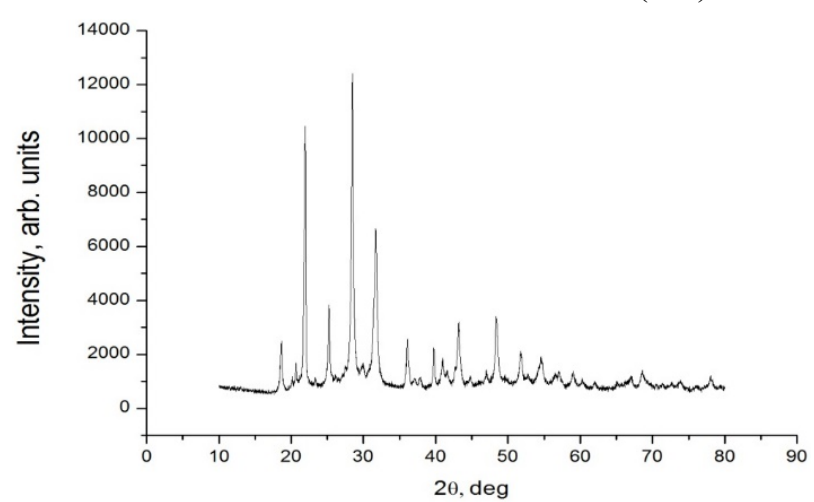

$\mathrm{a}$

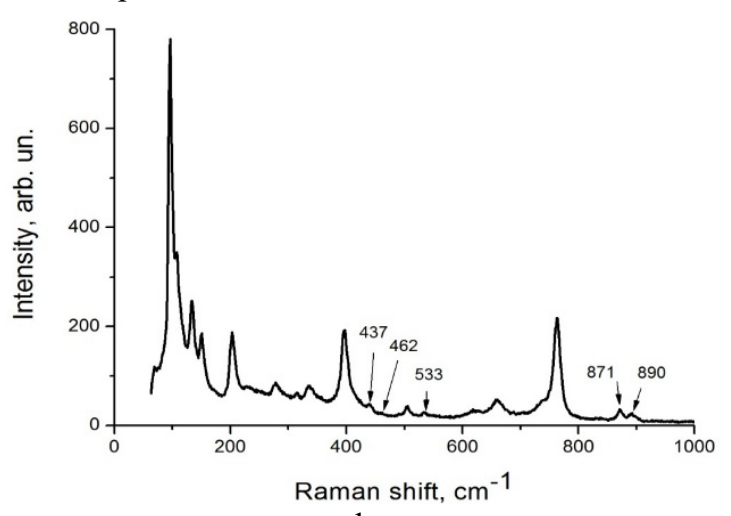

b

Figure 4. X-ray diffraction pattern (a) and Raman spectrum of the nanocomposite opal - $\mathrm{Bi}_{2} \mathrm{TeO}_{5}(\mathrm{~b})$, measured from the (111) surface of the sample

Comparative analysis of Raman spectra of opal nanocomposite - $\mathrm{Bi}_{2} \mathrm{TeO}_{5}$ with spectra of single crystals $\mathrm{Bi}_{12} \mathrm{SiO}_{20}$ (Venugopalan \& Ramdas, 1972), $\mathrm{Bi}_{4} \mathrm{Si}_{3} \mathrm{O}_{12}$ (Beneventi et al., 1995), polymorph $\alpha-$-, $\beta$-, $\delta$ - and $\gamma$ - $\mathrm{Bi}_{2} \mathrm{O}_{3}$ ( $\mathrm{Hardcastle}$ $\&$ Wachs, 1992) and phases $\alpha-, \beta-, \gamma$ - and $\delta-\mathrm{TeO}_{2}$ (Champarnaud-Mesjard et al., 2000) showed that the appearance of new lines in the Raman spectrum with frequencies $437 \mathrm{~cm}^{-1}, 462 \mathrm{~cm}^{-1}$ and $533 \mathrm{~cm}^{-1}$ can be associated with changes in the lengths of $\mathrm{Bi}-\mathrm{O}$ bonds in nanocrystals in opal pores, as well as with the formation of $\mathrm{Bi}_{4} \mathrm{Si}_{3} \mathrm{O}_{12}$ and $\mathrm{SiO}_{2}$ phases in opal pores due to the interaction of the melt with the surface of globules (Derhachov et al., 2019). The most intense bands in the Raman spectra of opal - $\mathrm{TeO}_{2}$ nanocomposite (Figure 5) correspond to the phase of $\alpha-\mathrm{TeO}_{2}$. At the same time new bands with frequencies are revealed 132, 225, 276, 333, $438,619 \mathrm{~cm}^{-1}$, which are assigned to the metastable phase $\gamma-\mathrm{TeO}_{2}$ (Abu et al., 2016; Champarnaud-Mesjard et al., 2000).

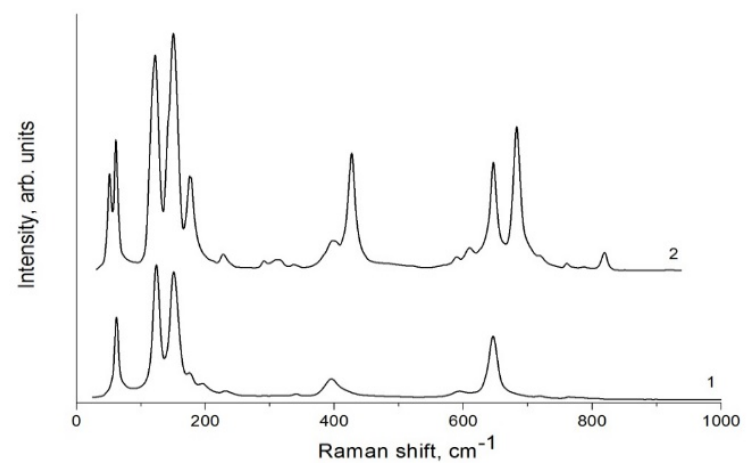

Figure 5. Raman spectra of $\alpha-\mathrm{TeO}_{2}$ polycrystalline powder (1) and $\mathrm{TeO}_{2}$ crystals in pores of synthetic opal (2) (Abu et al., 2013). The spectra are correspondent to the same quantity of tellurium dioxide in the excitation volume. 
Two weak bands with frequencies $871 \mathrm{~cm}^{-1}$ and $890 \mathrm{~cm}^{-1}$ observed in Raman spectra of opal - $\mathrm{Bi}_{12} \mathrm{SiO}_{20}$, opal$\mathrm{Bi}_{2} \mathrm{TeO}_{5}$ nanocomposites can be associated with the $\mathrm{Bi}_{4} \mathrm{Si}_{3} \mathrm{O}_{12}$ (Derhachov et al., 2019). Further more, the $\mathrm{SiO}_{2}$ phase is additionally formed in the pores of these nanocomposites (Derhachov et al., 2018; Derhachov et al., 2019). Raman spectra opal nanocomposites - $\mathrm{NaBi}\left(\mathrm{MoO}_{4}\right)_{2}$, opal - $\mathrm{Pb}_{3}\left(\mathrm{P}_{0.5} \mathrm{~V}_{0.5} \mathrm{O}_{4}\right)_{2}$, shown in Figure 6 .

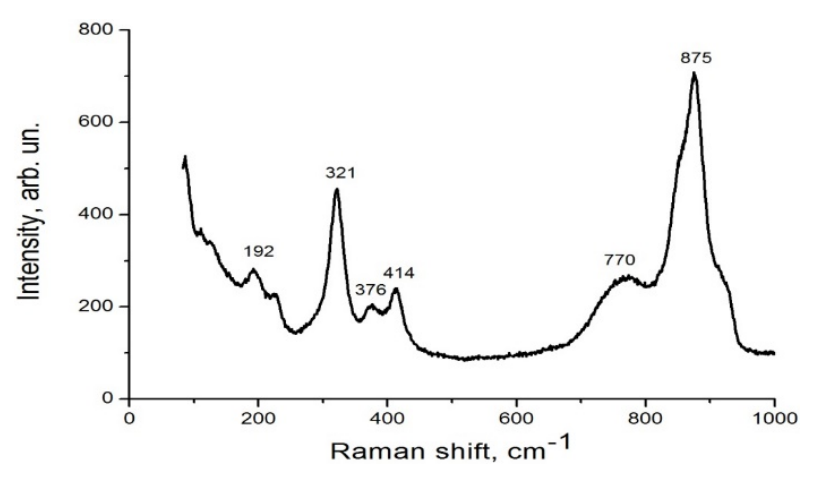

a

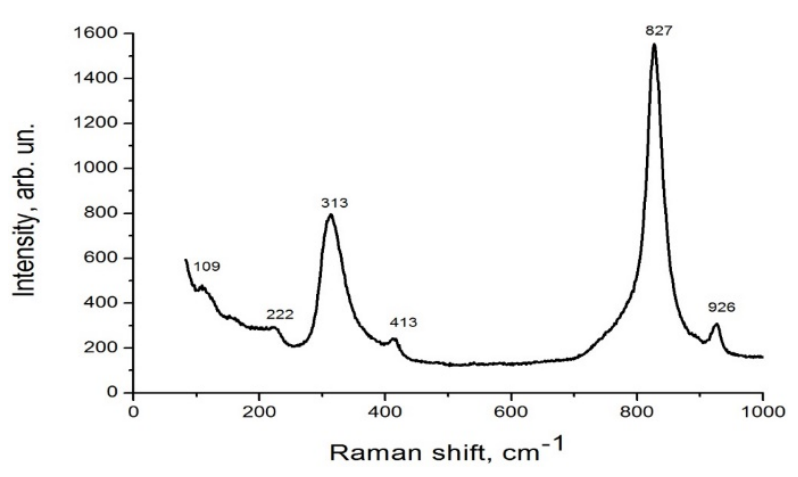

$\mathrm{b}$

Figure 6. Raman spectra opal nanocomposites - $\mathrm{NaBi}\left(\mathrm{MoO}_{4}\right)_{2}$ (a) and opal - $\mathrm{Pb}_{3}\left(\mathrm{P}_{0.5} \mathrm{~V}_{0.5} \mathrm{O}_{4}\right)_{2}(\mathrm{~b})$, measured from the (111) surface of the sample

The spectra indicate the frequencies of characteristic bands for crystals $\mathrm{NaBi}\left(\mathrm{MoO}_{4}\right)_{2}$ (Moiseenko et al., 2000) and $\mathrm{Pb}_{3}\left(\mathrm{P}_{0.5} \mathrm{~V}_{0.5} \mathrm{O}_{4}\right)_{2}$ (Hardcastle \& Wachs, 1992; Salje \& Iishi, 1977). The intensities of the spectra measured at different points to the (111) surface of the sample differed. In this case, the spectra were decomposed into spectral components. Comparative analysis of frequencies of spectral components Raman spectra of opal nanocomposites - $\mathrm{NaBi}\left(\mathrm{MoO}_{4}\right)_{2}$ and opal $-\mathrm{Pb}_{3}\left(\mathrm{P}_{0.5} \mathrm{~V}_{0.5} \mathrm{O}_{4}\right)_{2}$ and the analysis of single crystals allowed to reveal changes of frequencies of a number of oscillations in nanocomposites in comparison with single crystals (Moiseenko et al., 2000) $\left(\mathrm{cm}^{-1}\right)$ : 153/143; 227/236; 354/366; 645/681 (for opal nanocomposite - NaBi( $\left(\mathrm{MoO}_{4}\right)_{2}$ ) and 144/153, $163 / 175,343 / 352,412 / 406,779 / 771,926 / 931$ (for opal nanocomposite $\left.-\mathrm{Pb}_{3}\left(\mathrm{P}_{0.5} \mathrm{~V}_{0.5} \mathrm{O}_{4}\right)_{2}\right)$. The results for the opal - $\mathrm{Pb}_{3}\left(\mathrm{P}_{0.5} \mathrm{~V}_{0.5} \mathrm{O}_{4}\right)_{2}$ matrix nanocomposite are in good agreement with work data (Yevchik et al., 2018). The most probable reason for the change in the frequencies of a number of Raman bands is a change in stoichiometry during the distribution and crystallization of the melt in the pores of the opal matrix. The denominator shows the frequencies for the crystal. This may indicate a change in bond lengths Mo - O, P - O and V - O in tetrahedral complexes $\left[\mathrm{MoO}_{4}\right],\left[\mathrm{PO}_{4}\right]$ and $\left[\mathrm{VO}_{4}\right]$ in the process of nanocrystallization.

\section{Conclusions}

This paper examines the general regularity of phase formation of active dielectrics, since the bulk opals are introduced into the pores by the melt method, under the influence of capillary forces.

1. The molten pore filling method allows to fill the opal pores in one cycle $\sim 50$ vol. $\%$.

2. The substance in the pores of the opal is in a crystalline state, which is confirmed by both the characteristic Raman spectra and X-ray diffraction pattern.

3. The melt of $\mathrm{Bi}_{12} \mathrm{SiO}_{20}$ and $\mathrm{Bi}_{2} \mathrm{TeO}_{5}$ reacts actively with the surface of globules. The result is:

- for opal- $\mathrm{Bi}_{12} \mathrm{SiO}_{20}$ nanocomposite, the dominant phase of bismuth orthosilicate $\left(\mathrm{Bi}_{4} \mathrm{Si}_{3} \mathrm{O}_{12}\right)$ was revealed in opal pores according to Raman spectra and X-ray diffraction Pattern.

- for the opal - $\mathrm{Bi}_{2} \mathrm{TeO}_{5}$ nanocomposite, according to Raman spectra and X-ray diffraction pattern, thephases $\mathrm{Bi}_{4} \mathrm{Si}_{3} \mathrm{O}_{12}$ and $\mathrm{SiO}_{2}$ were additionally detected in the opal pores.

4. New lines in the Raman spectra of the opal - $\mathrm{TeO}_{2}$ nanocomposite have been identified and interpreted as a manifestation of the $\gamma-\mathrm{TeO}_{2}$ metastable phase.

5. The changes of oscillation frequencies for opal nanocomposites are revealed $-\mathrm{NaBi}\left(\mathrm{MoO}_{4}\right)_{2}$ and opal $\mathrm{Pb}_{3}\left(\mathrm{P}_{0.5} \mathrm{~V}_{0.5} \mathrm{O}_{4}\right)_{2}$, which may indicate a change in bond lengths Mo - O, P - O and V - O in tetrahedral complexes $\left[\mathrm{MoO}_{4}\right],\left[\mathrm{PO}_{4}\right]$ and $\left[\mathrm{VO}_{4}\right]$ during nanocrystallization. 
6. The difference in the intensity of the Raman spectra at different points of the sample surface has been established, which may be due to inhomogeneous filling of pores with melt, as well as to the effects of structural focusing of light.

\section{Acknowledgements}

I would like to submit my sincere gratitude to professor V.N. Moiseyenko (Oles Honchar, National UniversityUkraine)and,Deutsche Forschungsgemeinschaft for their generous grant through professor Dr.R.Holze and Dr. Raul David Rodriguez (Institute of Physics) for their permision to use Raman and Infrared facilities at Technische Universität Chemnitz, Institute of Chemistry. I would like also thank Nanoscopy center in Kuwait University for using their SEM.

\section{References}

Abu, S. B., Moiseyenko, V., Dergachov, M., Yevchik, A., \& Dovbeshko, G. (2013). Manifestation of metastable gamma- $\mathrm{TeO}_{2}$ phase in the Raman spectrum of crystals grown in synthetic opal pores. Ukrainian Journal of Physical Optics, 14(3), 119-124. https://doi.org/10.3116/16091833/14/3/119/2013

Astratov, V. N., Bogomolov, V. N., Kaplyanskii, A. A., Prokofiev, A. V., Samoilovich, L. A., Samoilovich, S. M., \& Vlasov, Y. A. (1995). Optical spectroscopy of opal matrices with CdS embedded in its pores: Quantum confinement and photonic band gap effects. Il Nuovo Cimento D, 17(11-12), 1349-1354. https://doi.org/10.1007/BF02457208

Beneventi, P., Bersani, D., Lottici, P. P., \& Kovacs, L. (1995). A Raman study of $\mathrm{Bi}_{4}\left(\mathrm{Ge}_{\mathrm{x}} \mathrm{Si}_{1-\mathrm{x}}\right)_{3} \mathrm{O}_{12}$ crystals. Solid state communications, 93(2), 143-146. https://doi.org/10.1016/0038-1098(94)00743-8

Bogomolov, V. N. (1978). Liquids in ultrathin channels (Filament and cluster crystals). Soviet Physics Uspekhi, 21(1), 77. https://doi.org/10.1070/PU1978v021n01ABEH005510

Champarnaud-Mesjard, J. C., Blanchandin, S., Thomas, P., Mirgorodsky, A., Merle-Mejean, T., \& Frit, B. (2000). Crystal structure, Raman spectrum and lattice dynamics of a new metastable form of tellurium dioxide: $\gamma-\mathrm{TeO}_{2}$. Journal of physics and chemistry of solids, 61(9), 1499-1507. https://doi.org/10.1016/S0022-3697(00)00012-3

Derhachov, M., Moiseienko, V., Kutseva, N., Sal, B. A., \& Holze, R. (2019). Fabrication and characterization of crystalline $\mathrm{Bi}_{2} \mathrm{TeO}_{5}-\mathrm{Bi}_{4} \mathrm{Si}_{3} \mathrm{O}_{12}-\mathrm{SiO}_{2}$ nanocomposite. The European Physical Journal Plus, 134(7), 370. https://doi.org/10.1140/epjp/i 2019-12898-0

Derhachov, M., Moiseienko, V., Kutseva, N., Sal, B. A., Holze, R., Pliaka, S., \& Yevchyk, A. (2018). Structure, Optical and Electric Properties of Opal-Bismuth Silicate Nanocomposites. Acta Physica Polonica A, 133(4), 847-850. https://doi.org/10.12693/APhysPolA.133.847

Domoratskii, K. V., Pastukhov, V. I., Kudzin, A. Y., Sadovskaya, L. Y., Rizak, V. M., \& Stefanovich, V. A. (2000). Raman scattering in the $\mathrm{Bi}_{2} \mathrm{TeO}_{5}$ single crystal. Physics of the Solid State, 42(8), 1443-1446. https://doi.org/10.1134/1.1307049

Gubin, S. P., \& Moiseev, I. I. (1987). Chemistry of clusters. Moscow: Nauka.

Gusev, A. I., \& Rempel', A. A. (2004). Nanocrystalline materials. Cambridge: Cambridge Int Science Publishing.

Hardcastle, F. D., \& Wachs, I. E. (1992). The molecular structure of bismuth oxide by Raman spectroscopy. Journal of Solid State Chemistry, 97(2), 319-331. https://doi.org/10.1016/0022-4596(92)90040-3

Kurdyukov, D. A., Grudinkin, S. A., Nashchekin, A. V., Smirnov, A. N., Trofimova, E. Y., Yagovkina, M. A., ... \& Golubev, V. G. (2011). Melt synthesis and structural properties of opal- $\mathrm{V}_{2} \mathrm{O}_{5}$ and opal- $\mathrm{VO}_{2}$ nanocomposites. Physics of the Solid State, 53(2), 428-434. https://doi.org/10.1134/S1063783411020144

Liu, H. C., \& Kuo, C. L. (1997). X-ray powder diffraction pattern of Bi-4 $\mathrm{Bi}_{4}\left(\mathrm{SiO}_{4}\right)_{3}$. Journal of Materials Science \& Technology, 13(2), 145-148.

Mercurio, D., El Farissi, M., Frit, B., \& Goursat, P. (1983). Étude structurale et densification d'un nouveau materiau piézoélectrique: $\mathrm{Bi}_{2} \mathrm{TeO}_{5}$. Materials chemistry and physics, 9(5), 467-476. https://doi.org/10.1016/0254-0584(83)90073-1

Moiseenko, V. N., Bogatirjov, Y. I., Jeryemenko, A. M., \& Akimov, S. V. (2000). Raman spectra of acoustooptic $\mathrm{NaBi}\left(\mathrm{MoO}_{4}\right)_{2}$. Journal of Raman Spectroscopy, 31(6), 539-541.

https://doi.org/10.1002/1097-4555(200006)31:6<539::AID-JRS550>3.0.CO;2-G 
Moiseienko, V., Derhachov, M., Sal, B. A., Holze, R., \& Brynza, M. (2016, August). Nanocomposites on the Base of Synthetic Opals and Nanocrystalline Phases of Bi-containing Active Dielectrics. In International Conference on Nanotechnology and Nanomaterials (pp. 661-674). Springer, Cham. https://doi.org/10.1007/978-3-319-56422-7_50

Moiseyenko, V. N., Brynza, N. P., Sal, B. A., Holze, R., \& Gorelik, V. S. (2018). Raman scattering in nanocomposites based on synthetic opal and nanocrystalline $\mathrm{Bi}_{2} \mathrm{TeO}_{5}$. Inorganic Materials, 54(12), 1250-1255. https://doi.org/10.1134/S0020168518120117

Moiseyenko, V., Yevchik, A. V., Dergachov, M., Spichak, O., \& Gorelik, V. (2015). The effects of disorder on the optical spectra of synthetic opals. In Nanoplasmonics, Nano-Optics, Nanocomposites, and Surface Studies (pp. 315-327). Springer, Cham. https://doi.org/10.1007/978-3-319-18543-9_22

Petrov, Y. I. (1986). Clusters and small particles. Moscow: Nauka.

Salje, E., \& Iishi, K. (1977). Ferroelastic Phase Transition in Lead Phosphat-Vanadate $\mathrm{Pb}_{3}\left(\mathrm{P}_{\mathrm{x}} \mathrm{V}_{1-\mathrm{x}} \mathrm{O}_{4}\right)_{2}$. Acta Cryst., A33, 399-408. https://doi.org/10.1107/S0567739477001065

Stöber, W., Fink, A., \& Bohn, E. (1968). Controlled growth of monodisperse silica spheres in the micron size range. Journal of colloid and interface science, 26(1), 62-69. https://doi.org/10.1016/0021-9797(68)90272-5

Venugopalan, S., \& Ramdas, A. K. (1972). Raman spectra of bismuth germanium oxide and bismuth silicon oxide. Physical Review B, 5(10), 4065-4079. https://doi.org/10.1103/PhysRevB.5.4065

Yevchik, A., Moiseyenko, V., Derhachov, M., Plaksin, S., \& Levchenko, R. (2018, September). Study of Raman Spectra of $\mathrm{Pb}_{3}\left(\mathrm{P}_{0.5} \mathrm{~V}_{0.5} \mathrm{O}_{4}\right)_{2}$ Crystallized in Nanoscale Opal Pores. In 2018 9th International Conference on Ultrawideband and Ultrashort Impulse Signals (UWBUSIS) (pp. 222-225). IEEE.

Zaytsev, K. I., Katyba, G. M., Yakovlev, E. V., Gorelik, V. S., \& Yurchenko, S. O. (2014). Band-gap nonlinear optical generation: The structure of internal optical field and the structural light focusing. Journal of Applied Physics, 115(21), 213505. https://doi.org/10.1063/1.4880299

\section{Copyrights}

Copyright for this article is retained by the author(s), with first publication rights granted to the journal.

This is an open-access article distributed under the terms and conditions of the Creative Commons Attribution license (http://creativecommons.org/licenses/by/4.0/). 